DOI: $10.15575 /$ ks.v2i3.9700

\title{
Persepsi Masyarakat Rural terhadap Profil Calon Presiden Dalam Pemilihan Presiden 2019
}

\author{
Robby Darwis Nasution ${ }^{1 *}$, Jusuf Harsono², Bambang Triono ${ }^{3}$ \\ ${ }^{123}$ Program Studi Ilmu Pemerintahan, Universitas Muhammadiyah Ponorogo, Jalan Budi Utomo No. 10, \\ Kabupaten Ponorogo, 63471 Indonesia. \\ *Corresponding Author Email: darwisnasution69@gmail.com
}

\begin{abstract}
The general election period is a period associated with a democratic party in which each voter determines the choice and many determinants are considered voting. In addition, the interference of the media in framing an election news also colored this 2019 election contestation. But does this apply in all societies? Whereas in the trural area, it seems that the influence of the media is not touched at all. So from that problem formulation in this research is how is the perception of rural communities towards the profile of presidential candidates in 2019? The method used is qualitative research with data collection techniques with in-depth interviews, observation and documentation. The final goal of this study is to find out how people's perceptions of the profile of presidential candidates in the 2019 presidential election. The conclusion of this study is that informants from all three age groups have and put great hopes on each candidate they will choose in the 2019 election. On one hand, the media will help raise the profile of the candidates who will compete in the general election, but on the other hand, the media will also be a weapon destroying the profile of a candidate if the aim is to spread hoax news related to the bad profile of the prospective leader.
\end{abstract}

Keywords: Election, Profile of Presidential Candidates, Perception, Rural Communit

\begin{abstract}
ABSTRAK
Pemilu selalu menyajikan fenomena yang menarik untuk diteliti terutama pemilu di Indonesia yang penuh dengan pergerakan politik. Masa pemilihan umum adalah masa yang dikaitkan dengan pesta demokrasi dimana setiap voters menentukan pilihan dan banyak penentu menjadi pertimbangan memilih. Selain itu, campur tangan media dalam membingkai sebuah berita pemilu juga ikut mewarnai kontestasi pemilu 2019 ini. Tetapi apakah hal ini berlaku di semua masyarakat? Sedangkan di wilayah rural (pedesaan) seolah tidak terjamah pegaruh media sama sekali. Maka dari itu rumusan masalah dalam penelitian ini adalah bagaimana persepsi masyarakat rural terhadap profil calon presiden tahun 2019? Metode yang digunakan adalah penelitian kualitatif dengan teknik pengumpulan data dengan wawancara mendalam, observasi serta dokumentasi. Tujuan akhir dari penelitian ini adalah mengetahui bagaimana persepsi masyarakat terhadap profil calon presiden dalam pilpres 2019. Kesimpulan dari penelitian ini adalah informan dari ketiga golongan usia memiliki serta menaruh harapan besar kepada setiap calon yang akan mereka pilih pada pemilu 2019. Disatu sisi, media akan membantu mengangkat profil dari calon yang akan bertarung dalam pemilihan umum, tetapi disisi lain media juga akan menjadi senjata penghancur profil suatu calon jika tujuannya adalah menyebarkan berita hoax terkait dengan keburukan profil calon pemimpin tersebut.
\end{abstract}

Kata Kunci: Pemilu, Profil Calon Presiden, Persepsi, Masyarakat Rural

\section{PENDAHULUAN}

Sayfa Aulia mengatakan bahwa kemenangan Pilpres adalah keberhasilan menarik simpati publik secara langsung yang diperoleh dari pencitraan bersifat personal. Gaya muda, penampilan kasual, kemajuan karier politik, dan harapan kebaruan adalah gimmick politik yang pengaruhnya dengan cepat bisa membesar lewat media masssa (televisi, cetak, dan media sosial). Pilihan politik per individu yang tertarik terhadap hal-hal semacam itu terkonversi langsung jadi pilihan atas sosok presiden (Achidsti,

* Copyright (c) 2020 Robby Darwis Nasution, Jusuf Harsono, Bambang Triono

This work is licensed under a Creative Commons Attribution-ShareAlike 4.0 International License.

Diterima: 28 September 2020; Direvisi: 5 November 2020; Disetujui: 7 November 2020 
2018). Kekuatan para calon yang maju dalam pesta demokrasi ini patut mempertimbangkan beberapa hal diantaranya kekuatan media, kekuatan komunitas, dan antitesis gaya kepemimpinan. Ukuran kekuatan media melihat bagaimana elektabilitas capres dinaikkan melalui pencitraan. Popularitas capres adalah satu faktor di antara faktor lain, yaitu kekuatan parpol dan jaringannya sebagai kunci kekuatan politik (Achidsti, 2018).

Kegiatan besar yang bertajuk Reuni 212 yang dilaksanakan dikawasan monas Jakarta telah menjadi perhatian utama bagi BAWASLU ataupun calon Presiden yang maju dalam Pilpres 2019 (Fautanu, Buhori, \& Gunawan, 2020). Hal ini karena masa Reuni 212 memiliki jumlah yang sangat besar dan pengerahan massa yang militan ini merupakan peluang besar bagi kedua calon yang maju sebagai penyumbang suara. Tetapi Reuni 212 telah menyatakan tidak akan ada unsur politik dalam kegiatan reuni 212 meskipun calon presiden nomor urut 2 yaitu Prabowo Subianto turut diundang disana tetap calon tersebut tidak diperbolehkan untuk berkampanye (Adiyanto, 2020). Seperti yang dikutip dalri laman BBC bahwa kesempatan pidato yang diberikan kepada Prabowo Subianto selama 3 menit hanya berisi ucapan terimakasih karena telah diundang dalam acara reuni 212. (BBC, 2019) Acara besar seperti ini memang salah satu jalan masuk bagi calon untuk bisa mmembangun profil dimata masyarakat sehingga kekuatan militansi akan berimbas kepada besarnya suara yang didapatkan hal itu dapat digambarkan pada tabel 1 .

Tabel 1. Hasil Survey dari Litbang Kompas dan Liputan 6

\begin{tabular}{|c|c|c|}
\hline Survey & Hasil & Keterangan \\
\hline Litbang Kompas & $\begin{array}{l}\text { Elektabilitas } \\
\text { Joko Widodo dan Ma'aruf Amin ( 52,6 } \\
\% \text { ) } \\
\text { Prabowo Subianto dan Sandiaga } \\
\text { Salahuddin Uno (32,7) } \\
\text { Belum Menentukan Pilihan (14,7) }\end{array}$ & $\begin{array}{l}\text { Menurut Litbang } \\
\text { Kompas, Total pemilih } \\
\text { yang masih ragu } \\
\text { terhadap pilihannya } \\
\text { bisa mencapai } 46,8 \% \text {, } \\
\text { yang mana membuat } \\
\text { hasil akhir dari } \\
\text { pemilihan masih sulit } \\
\text { di tentukan. (Kuwado, } \\
\text { 2018) }\end{array}$ \\
\hline \multirow[t]{2}{*}{ Liputan 6} & $\begin{array}{l}\text { Elektabilitas } \\
\text { Joko Widodo dan Ma'aruf Amin ( 47,7 } \\
\% \text { ) }\end{array}$ & 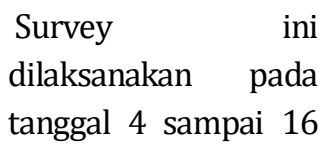 \\
\hline & $\begin{array}{l}\text { Prabowo Subianto dan Sandiaga } \\
\text { Salahuddin Uno }(35,5) \\
\text { Belum Menentukan Pilihan }(16,8)\end{array}$ & $\begin{array}{lr}\text { November } & 2018, \\
\text { dengan } & \text { peserta } \\
\text { survey } & \text { merupakan } \\
\text { warga } & \text { yang } \\
\text { mempunyai hak pilih } \\
\text { pada } & \text { pemilihan } \\
\text { presiden } & \text { (Liputan6, } \\
2018) . & \end{array}$ \\
\hline
\end{tabular}

Sumber : Hasil Olah Peneliti 2020 


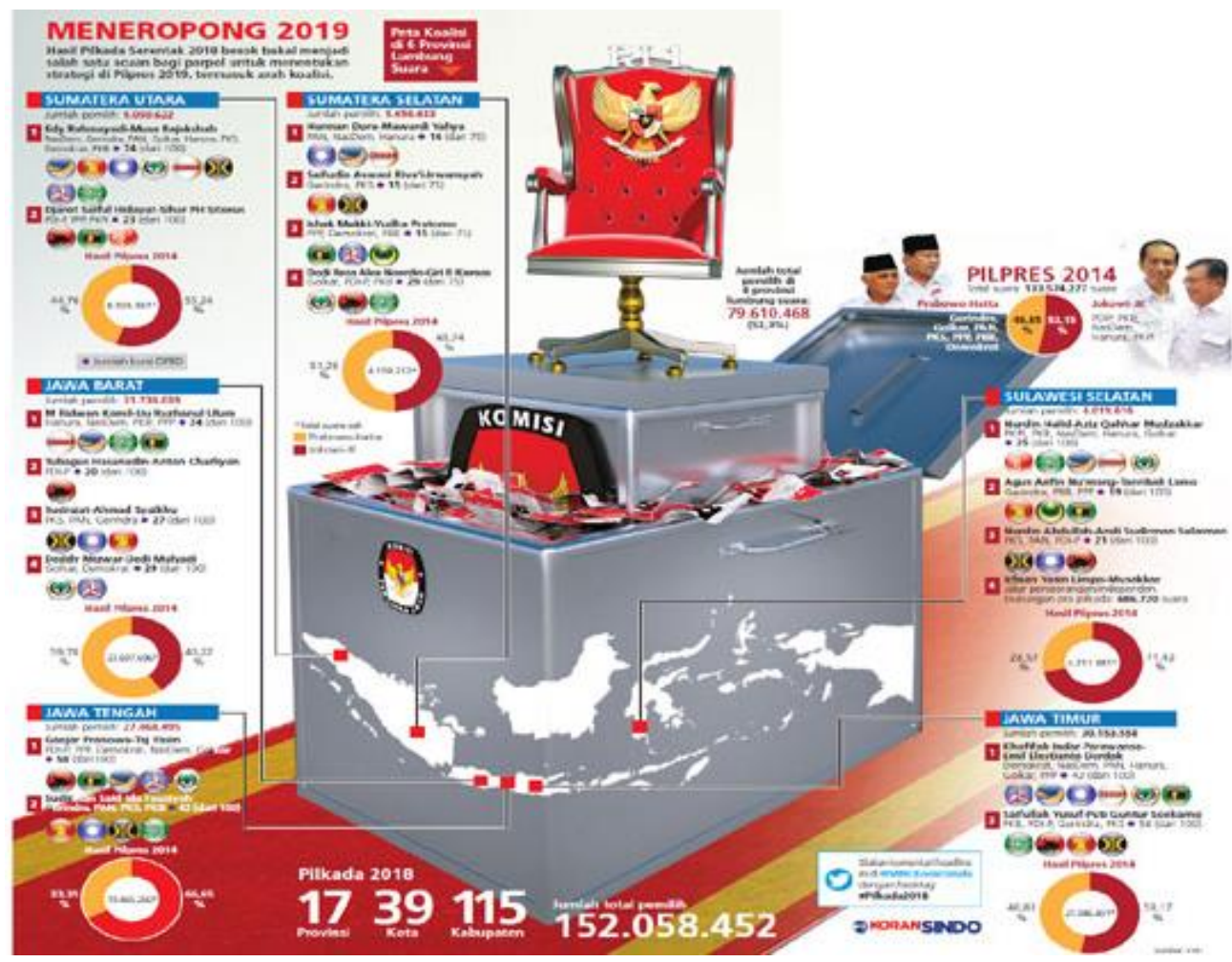

Gambar. 1 Gambaran Suara Pemilihan

Sumber : Koran Sindo (Sindo, 2018)

Gambar 1 menjelaskan bagaimana komplektisitas pemegang suara tiap partai di beberapa provinsi di Indonesia. Darigambar ini juga terlihat bagaimana perolehan suara dan kekuatan dari setiap partai yang ikut dalam pemilu 2019.

Usaha saling serang antara kedua kubu yang berlaga di Pilpres 2019 menjadi sajian yang sangat menarik karena hal itu juga secara tidak langusng akan mempengaruhi elektabilitas kedua calon. Seperti kasus hoak Ratna Sarumpaet yang notabene adalah relawan salah satu psangan calon presiden maka ini akan menjadi alat yang bagus bagi kubu lawan untuk menyerang dan tentu harapannya adalah menurunkan tingkat kepercayaan terhadap paslon tersebut. (Liputan6, 2018)

Menurut Sayfa Aulia (Dosen FISIP Universitas Sebelas Maret), pilpres 2014 adalah polarisasi keras antara gaya politik dua kelompok besar. Hasil Pilpres berlanjut hingga ke tahap "rivalitas intrapemerintahan". Konflik politik Koalisi Indonesia Hebat (KIH) dan Koalisi Merah-Putih (KMP) adalah contoh betapa kerasnya pertarungan yang berlanjut ke hulu proses demokrasi: DPR RI. Kubu yang satu boleh memenangkan kursi presiden (eksekutif), tetapi kubu lainnya mengunci fungsi perundangan dan anggaran (via legislatif). Kondisi semacam ini menunjukkan bagaimana masing-masing kelompok politik punya gaya politik yang khas. Ada banyak unsur dalam gaya politik, antara lain mesin ekonomi (kepemilikan sumber daya bisnis), mesin politik (jaringan dan konstituen), sampai brandyang ditanamkan pada publik (visi, janji, label figur, dan komunikasi politiknya). (Achidsti, 2018)

Ukuran kedua terkait cara parpol memaksimalkan jaringan politik lokal (basis massa) dan pengelolaan isu. Jika ditambah jumlah anggota dewan dan kepala daerah, gabungan parpol non-Jokowi relatif masih sama kuatnya dalam jaringan politik lokal. Asumsikan jika kekuatan ke bawah relatif sama, 
maka pertarungannya adalah soal mengelola isu sehingga bisa mempengaruhi cara pandang publik dalam menentukan presiden yang pantas. Kekuatan ketiga adalah isu alternatif dimana hal ini akan menjadi faktor penting dalam siklus politik yang dalam konteks ini, Jokowi pada Pilpres 2014 dianggap semacam "antitesis" (kebalikan) dari kepemimpinan figur militer SBY (Achidsti, 2018).

Segala hiruk pikuk dari pemilihan umum ini tentu akan semakin marak di kota-kota dengan akses informasi yang mudah tetapi mungkin saja informasi yang cenderung terbatas seperti wilayah pedesaan tidak akan berlaku isu-isu ini dimana kecenderungan stigma yang melekat pada masyarakat pedesaan adalah identik dengan sikap yang kolot dan tradisional (Nasution, 2016, p. 36). Jika melihat dari beberapa literatur yang telah ada seperti diungkapkan Siska Sasmita dengan judul artikel "Peran Informasi Politik Terhadap Partisiapasi Pemilih Pemula dalam Pemilu/Pemilukada" Artikel yang diterbitkan oleh Jurnal Ilmiah Administrasi Publik dan Pembangunan ini membahas tentang terkerkaitan antara ketersediaan informasi publik terhadap siap pemilih pemula dalam menentukan pilihannnya dalam pemilu. Kesimpulan dari artikel ilmiah ini adalah pemilih pemula masih dipengaruhi ikatan emosional dan komersial dalam menentukan pilihan politiknya. Kecenderungan irrasional dari pemilih pemula ini hendaknya dapat dihindari melalui pendidikan politik yang secara intensif dilakukan pemerintah dan partai politik. Pemerintah tidak bisa melepaskan tanggungjawab pelaksanaan pendidikan politik kepada LSM. Partai politik pun harus mampu membuktikan komitmennya kepada pemilih pemula hingga pemilih pemula tidak enggan berpartisipasi dalam kehidupan politik dan kenegaraan (Sasmita, 2011).

Beberapa penelitian terdahulu seperti penelitian oleh Sarbaini dalam artikelnya membahas tentang persepsi masyarakat pedesaan terhadap politik khusunya di Desa Tenantang dimana masyarakat Desa ternyata memiliki pandangan yang negative terhadap partai politik sehingga kesimpulan dari artikel ilmiah ini adalah Persepsi masyarakat terhadap partai politik di desa Terantang Kecamatan Mandastana Kabupaten Barito Kuala, yaitu masyarakat Desa Terantang dalam memandang partai politik mempunyai sikap yang Politis, Apatis, dan Logis. (Sarbaini, 2015), Selain itu, Ani Mustaghfiroh juga melakukan riset dengan fokus terhadap persepsi masyarakat terhadap kepala desa sebagai penggerak politik. Yang menghasillan bahwa dengan keterlibatanya sebagai penggerak politik, telah memberi pengaruh pada persepsi tersendiri dalam masyarakat terhadap kepala desa (Mustaghfiroh, 2011).

Anna Dameria Turnip dalam artikelnya yang berjudul "Persepsi Masyarakat Terhadap Peranan Partai Politik Dalam Pemilihan Kepala Daerah di Desa Branti Kecamatan Natar Kabupaten Lampung Selatan Tahun 2015" Menunjukkan masyarakat memiliki pemahaman, tanggapan dan harapan yang baik terhadap peran partai politik. Di desa branti lampungs selatan tahun 2015. Kelemahan dari tulisan ini adalah hanya melihat sejauh baik buruk tetapi tidak melihat secara mendalam tentang bagaimana pendapat masyarakat dan juga pandangan masyarakat terkait dengan partai politik itu sendiri sehingga hasil yang didapatkan masih sangat dangkal (Dameria, 2016).

Dengan melihat pemetaan literature yang telah ada tentang persepsi masyarakat rural tetang pemilihan presiden masih belum banyak didapati yang secara spesifik membahas diranah masyarakat rural sehingga penelitian ini akan menjadi pijakan pertama dalam case study ini. Selanjutnya jika kita melihat juga dibeberapa literature diatas masih sebatas mendeskripsikan persepsi itu diranah yang paling dangkal yaitu di ranah baik dan buruk atau bahkan orang mengenal atau tidak saja tidak sampai bagaimana suatu profil calon atau profil partai politik akan mempengaruhi individu dan juga masuk menjadi harapan utama dalam sebuah pemilihan umum. Untuk melihat hal itu maka perlu dalam penelitian ini kembali membahas tentang pengertian dari Persepsi Masyarakat sehingga dapat memunculkan arti dana rah yang jelas dalam penelitian ini. 
Ditengah terpaan pencitraan atau isu hoax ini bagaimana kita melihat lebih jauh tentang persepsi masyarakat rural (pinggiran) terhadap profil calon presiden pada pemilu 2019. Berdasarkan latarbelakang diatas maka sangat menarik sekali jika melihat lebih jauh tentang persepsi masyarakat rural (pinggiran) terhadap profil calon presiden pada pemilu 2019?

\section{METODE PENELITIAN}

Penelitian ini menggunakan pendekatan deskriptif kualitatif untuk memperoleh gambaran yang bersifat komprehensif yang mendalam tentang persepsi masyarakat terhadap profil calon presiden dalam pemilu 2019. Hal ini sejalan dengan pendapat Bogdan dan taylor yang menyatakan "metode kualitatif" sebagai prosedur penelitian yang menghasilkan data deskriftif berupa kata-kata tertulis atau lisan dari orang-orang dan perilaku yang dapat di amati. (Moleong, 2002, p. 3) Dengan demikian penelitian ini akan lebih sesuai dengan menggunakan pendekatan kualitatif, yaitu data yang dikumpulkan berdasarkan ungkapan, bahasa, cara berpikir dan pandangan masyarakat.

Teknik pengumpulan data dan informasi dari informan menggunakan metode observasi dan wawancara mendalam (indepth interview). Teknik analisis data dengan menggunakan azas kualitatif fenomenologis, yaitu dengan tahap-tahap : a) Mereduksi data, yaitu mengumpulkan dan menyajikan datadata yang diperoleh menjadi fakta-fakta yang bisa diamati, obyektif dan sesuai dengan kebutuhan; b) Interprestasi data, yaitu mengolah dan mencari hubungan diantara fakta-fakta yang telah terkumpul, mengembangkanya untuk mencari kesesuaian dengan hipotesa (rumusan masalah) yang sudah ada; dan c) Membuat kesimpulan berdasarkan hasil analisis dari tahap sebelumnya.

Penelitian tentang persepsi masyarakat terhadap profil calon presiden dalam pemilu 2019 ini akan bertempat di Kabupaten Ponorogo dan dan diambil sampel secara acak. Penentuan wilayah Kabupaten Ponorogo sangat penting mengingat daerah ini bukan merupakan pusat kota dengan background masyarakat yang beragam sehingga validitas dari hasil penelitian diharapkan bisa mewakili seluruh lapisan masyrakat.

\section{HASIL DAN PEMBAHASAN}

Ada tiga faktor yang mempengaruhi persepsi masyarakat dimana menurut Simanjuntak yaitu: (Sarbaini, 2015, p. 738) yaitu : Pelaku persepsi, Target atau objek dan Situasi. Menurut Simanjuntak (Robbins, 2011:88) Persepsi dapat didefinisikan sebagai proses dengan mana individu-individu mengorganisasikan dan menafsirkan kesan indera mereka agar memberi makna kepada lingkungan mereka. Jadi pengertian persepsi masyarakat dapat disimpulkan sebagai tanggapan atau pengetahuan lingkungan dari kumpulan individu-individu yang saling bergaul dan berinteraksi karena mempunyai nilai-nilai, norma-norma, cara-cara dan prosedur merupakan kebutuhan bersama berupa suatu sistem adat istiadat tertentu yang bersifat terus menerus dan terikat oleh suatu identitas bersama yang diperoleh melalui interpretasi data indera. (Sarbaini, 2015, p. 737)

Menurut Sarbaini, persepsi sangat dipengaruhi oleh unsur subjektif orang yang mempersepsikan, sehingga persepsi selalu mengarah pada fakta spesifikasi pribadi. Oleh karena itu, penerimaan terhadap objek yang sama akan ditanggapi atau dipersepsi berbeda oleh kelompok yang satu dan lainnya atau orang yang satu dengan lainnya. (Sarbaini, 2015, p. 738)

Berdasarkan hasil wawancara informan usia 17-25 tahun dapat diketahui analisis profil calon presiden 2019, masing-masing profil pasangan calon memiliki latar belakang yang berbeda-beda sehingga masyarakat memiliki daya tarik tersendiri dari masing-masing pasangan calon. Pasangan calon no 1 
memiliki profil dengan gayanya yang merakyat, sederhana dan jujur. Pasangan calon no 2 memiliki profil mantan jenderal militer yang mempunyai jiwa kepemimpinan yang cinta NKRI dan didukung oleh wakil yang berkompeten karena masih muda dan memiliki track record yang baik. Sedangkan sosok yang harus ada dalam seorang pemimpin adalah pemimpin yang tegas, merakyat, dan bijaksana dalam mengambil setiap keputusan, seorang pemimpin yang bisa mempimpin dirinya sendiri dan memimpin orang banyak. Setiap profil dari seorang calon presiden itu penting dan berpengaruh dalam pengambilan keputusan siapa yang akan mereka pilih. Sehingga latar belakang masing-masing pasangan calon membuat masyarakat berkomitmen terhadap pilihannya sendiri sehingga mereka tidak berpengaruh dengan isuisu negatif yang berkembang saat mendekati pemilu. Masyarakat tertarik dengan kedua calon yang memiliki visi dan misi sera janji-janji yang menarik dengan gaya masing-masing untuk memajukan bangsa Indonesia 5 tahun kedepan.

Menurut informasi dari informan diatas kita semakin tahu bahwa sekarang banyak pemilihpemilih yang cerdas dengan tidak mudahnya terpengaruh dengan hoax-hoax yang beredar di media televisi maupun media sosial. Mereka memilih yakin dengan calon yang mereka yakini baik untuk Indonesia kedepannya. Saat ini media massa memang sangat berperan dalam menentukan kemenangan calon presiden tetapi sebagian informan juga mengatakan mereka tidak akan terpengaruh oleh isu-isu yang beredar karena mereka mempunyai keyakinan pribadi masing-masing.

Kemenangan calon presiden akan berpengaruh terhadap kehidupan masyarakat melalui kebijakan-kebijakan yang akan dibuat oleh pemerintahannya (Suhaimi, 2019). Masyarakat sangat mengharapkan janji-janji calon presiden terealisasi karena jika memang janji itu terealisasi akan sangat berpengaruh terhadap kehidupan masyarakat kepada kehidupan yang lebih baik lagi. Tak sedikit informan menganggap janji-janji hanya digunakan menarik simpati masyarakat agar calon terpilih, tetapi akan lupa dengan janji-janji itu ketika sudah terpilih sebagai Presiden.

Setelah data yang kami cantumkan dari informan usia 25-35 tahun dapat kami analisis bahwa Profil dari Capres dan Cawapres sangat menentukan hak pilih masyarakat hal ini senada dengan penelitian yang dilakukan oleh Juditha yang menyatakan peran profile dari masing - masing calon mempunyai pengaruh yang cukup kuat pada penentuan seorang pemegang hak suara untuk memilih calon tersebut (Juditha, 2014), karena kebanyakan masyarakat sangat tertarikterhadap profil dari kedua pasangan calon presiden dan calon wakil presiden. Adanya profil dari kedua paslon Capres dan Cawapres sangat membantu masyarakat untuk mengetahui visi misinya dan membantu masyarakat untuk menentukan pilihannya. Presiden dan Wakil presiden yang memiliki kepribadian yang jujur, bijaksana, adil, tegas, bertanggung jawab dan mampu mengayomi masyarakat kalangan bawah, dan yang terpenting harus mempunyai kepemimpinan yang baik yang masyarakat inginkan.

Peran media juga sangat penting dimasa-masa sekarang apalagi dimasa pemilu seperti ini (Jati, 2013). Karena banyak masyarakat yang melihat kampanye dan profil dari kedua pasangan calon Presiden dan calon Wakil Presiden dari media terutama dari televisi dan media internet seperti sosial media (instgram, whatsapp, line, facebook). Namun dengan adanya peran media di masa sekarang atau dimasa pemilu ini banyak sekali beredar isu-isu negatif yang diarahkan terhadap ke 2 pasangan calon Presiden dan Wakil Presiden. Namun walaupun banyak isu-isu negatif yang ada di media yang diarahkan terhadap ke 2 pasangan calon Presiden dan calon Wakil Presiden masyarakat tidak sama sekali terpengaruh karena mereka beranggapan bahwasanya isu-isu negatif tersebut belum tentu benar dan masyarakat tetap berpegangan pada keyakinan diri sendiri untuk menentukan pilihannya.

Masyarakat hanya berharap kepada presiden yang terpilih nanti agar mampu menajalankan janjijanjinya dan visi misinya ketika kampanye dari situ masyarakat juga berharap dari visi misi presiden yang 
terpilih nanti dapat berdampak pada masyarakat Indonesia khususnya masyarakat kalangan bawah dan masyarakat juga berharap presiden yang jadi nanti bisa membawa Indonesia lebih maju lagi.

Berdasarkan hasil wawancara yang telah dilakukan oleh peneliti kepada masyarakat yang berusia 38-50. Terkait persepsi masyarakat terhadap profil pasangan calon presiden 2019, mereka rata-rata berpendapat bahwa ada yang menarik perhatian mereka dari profil pasangan calon Presiden 2019. Sedangkan mengenai harapan terhadap sosok seorang presiden yang akan memimpin bangsa nantinya yaitu harus memimpin Indonesia ialah sosok yang bisa jujur, adil, berwibawa dan mampu mengayomi masyarakatnya. Mereka beranggapan pula bahwa profil dari calon presiden merupakan hal yang penting guna memenangkan pemilihan umum. Selain itu terkait isu negatif yang beredar terhadap kedua pasangan capres maupun cawapres masyarakat tidak merasa terpengaruh terhadap isu yang beredar karena mereka beranggapan isu-isu negatif yang beredar belum benar adanya. Mereka juga beranggapan jika calon yang mereka pilih dalam pemilu jika menang akan mempengaruhi kehidupan masyarakat.

Rata-rata masyarakat dalam menentukan pilihannya yaitu melalui keyakinan diri sendiri dengan mengakses media sebagai sumber informasi guna memantapkan keyakinan mereka terhadap pilihan calon presiden dan wakil presiden yang mereka akan pilih nantinya. Selanjutnya mengenai harapan jika capres dan cawapres yang akan dipilih nanti menang ialah lebih peduli dan mampu mengayomi masyarakat terutama masyarakat kalangan bawah. Sedangkan terkait janji-janji yang di ucapkan capres maupun cawapres mereka hanya berharap akan dilaksanakan. Terkait perubahan apa yang diharapkan setelah calonnya menang tentunya ialah memperhatikan janji-janji yang sudah di canangkan ketika pemilu.

\section{SIMPULAN}

Kesimpulan akhir dari penelitian ini adalah profil dari setiap calon pemimpin terutama pada pemilihan Presiden akan menjadi keutamaan dalam menentukan sikap pemilih. Ciri khas yang melekat dalam seriap calon menjadi penguat dari profil yang mereka miliki. Penguatan profil dari calon menurut penelitian ini sangat efektif jika dilakukan melalui media sosial ataupun melalui media elektornik lainnya. Tetapi kembali lagi bahwa profil asli dari seorang calon akan menentukan sikap pemilih dimana jika profil aslinya sesuai budaya dan pola masyarakat pada saat itu maka baik pula profil yang akan terbentuk. Selain itu, traumatik dari sebuah profil juga ikut menentukan sikap pemilih dimana jika rakyat Indonesia akan sangat trauma dengan pemimpin berlatar belakang militer karena traumatik dengan era orde baru dan mereka tidak ingin era itu terulang kembali dibawah kepemimpinan militer.

Disatu sisi, media akan membantu mengangkat profil dari calon yang akan bertarung dalam pemilihan umum, tetapi disisi lain, media juga akan menjadi senjata penghancur profil suatu calon jika tujuannya adalah menyebarkan berita hoax terkait dengan keburukan profil calon pemimpin tersebut. Permainan media oleh pihak-pihak yang tidak bertanggungjawab tersebut akan secara masif menggiring opini publik jika berita hoax tersebt diberitakan secara terus-menerus. Tetapi pada penelitian ini menyimpulkan bahwa dua range usia tidak terpengaruh dengan berita hoax tetapi di informan di usia tua terpengaruh terhadap berita yang masiv tersebut. Sebagi penutup dari kesimpulan ini, peneliti ingin menyimpulkan bahwa memang benar media memberikan pengaruh terhadap penggiringan opini publik tetapi profil yang melekat pada seorang calon memang sangat sulit untuk ditumbangkan oleh media selama calon tetap menjaga profil tersebut sampai dengan hari pencoblosan. Sentimen terhadap profil calon pada akhirnya membawa pada pemilih untuk menjadikan mereka semakin militan. 


\section{DAFTAR PUSTAKA}

Achidsti, S. A. (2018, April 26). Serangan Darat dan Udara dalam Pemilu 2019. Retrieved from https://tirto.id/: https://tirto.id/serangan-darat-dan-udara-dalam-pemilu-2019-cJpC

Adiyanto, W. (2020). SIKAP MEDIA MENGENAI AKSI REUNI 212 Analisis Framing Aksi Reuni 212 pada Cnnindonesia. com dan Republika. co. id. . Jurnal Ilmu Komunikasi AKRAB, 5(1).

BBC. (2019, 12 12). PRABOWO SEBUT 'TIDAK BOLEH KAMPANYE' DI REUNI 212, RIZIEQ SERUKAN 2019 GANTI PRESIDEN. Retrieved from www.bbc.com: https://www.bbc.com/indonesia/indonesia-46416341

Dameria, A. (2016). PERSEPSI MASYARAKAT TERHADAP PERANAN PARTAI POLITIK DALAM PEMILIHAN KEPALA DAERAH. Lampung: Universitas Lampung.

Fautanu, I., Buhori, M., \& Gunawan, H. (2020). Politik Identitas dalam Pilkada DKI Jakarta Tahun 2017: Perspektif Pemikiran Politik Nurcholish Madjid. Politicon : Jurnal Ilmu Politik, 87-112.

Jati, W. R. (2013). Politik Persuasif Media: Peran Media Dalam Pemilu Presiden Indonesia 20012009 Media And Political Persuasion: The Role Of Media In Indonesia Presidential Campaign 2001-2009. E-journal LIPI, 10(2), 15.

Juditha, C. (2014). Penilaian Masyarakat Sulawesi Selatan Terhadap Kredibilitas Komunikator Politik Calon Presiden dan Wakil Presiden Republik Indonesia 2014. Pekommas, 17(3).

Kuwado, F. J. (2018, Oktober 24). Survei "Kompas": Jokowi-Ma'ruf 52,6 Persen, Prabowo-Sandi 32,7 Persen . Retrieved from https://nasional.kompas.com: https://nasional.kompas.com/read/2018/10/24/06552501/survei-kompas-jokowimaruf-526-persen-prabowo-sandi-327-persen.

Liputan6. (2018, November 27). Surei Median: Elektabilitas Jokowi-Ma'ruf 47,7 Persen, PrabowoSandi 35,5 Persen. Retrieved from https://www.liputan6.com/: https://www.liputan6.com/pilpres/read/3768843/survei-median-elektabilitas-jokowimaruf-477-persen-prabowo-sandi-355-persen

Moleong, L. (2002). Metodologi Penelitian Kualitatif. Bandung: PT. Remaja Rosdakarya.

Mustaghfiroh, A. (2011). Persepsi Masyarakat Terhadap Kepala Desa Sebagai Penggerak Politik. Yogyakarta: Universitas Negeri Yogyakarta.

Nasution, R. D. (2016). PENGARUH KESENJANGAN DIGITAL TERHADAP PEMBANGUNAN PEDESAAN (RURAL DEVELOPMENT). Jurnal Penelitian Komunikasi dan Opini Publik, 31-44.

Sarbaini, H. M. (2015). PERSEPSI MASYARAKAT TERHADAP PARTAI POLITIK DI DESA TERANTANG KECAMATAN MANDASTANA KABUPATEN BARITO KUALA. Jurnal Pendidikan Kewarganegaraan, 735-742.

Sasmita, S. (2011). PERAN INFORMASI POLITIK TERHADAP PARTISIPASI PEMILIH PEMULA DALAM PEMILU/PEMILUKADA. Jurnal Ilmiah Administrasi Publik dan Pembangunan, 217224.

Sindo, K. (2018, Juni 26). Pilkada Mempengaruhi Peta Pilpres. Retrieved from https://nasional.sindonews.com/:

https://nasional.sindonews.com/read/1316368/12/pilkada-pengaruhi-peta-pilpres$1529975635 / 15$

Suhaimi, E. (2019). EKSISTENSI PEMERINTAHAN PARTAI DALAM SISTEM KETATANEGARAAN INDONESIA. Nurani: Jurnal Kajian Syari'ah dan Masyarakat, 19(2), 173-184. 